\title{
Comunicaciones y confianza: ¿información 0 identidad? El caso del sector vitivinícola chileno hacia el mercado chino*
}

\section{Claudia Labarca ${ }^{1}$ Rodrigo Rojas ${ }^{2}$}

Recibido: 2016-01-05

Enviado a pares: 2016-01-13
Aprobado por pares: 2016-06-27

Aceptado: 2016-07-23

DOI: 10.5294/pacla.2017.20.2.10

Para citar este artículo / to reference this article / para citar este artigo Labarca, C. y Rojas, R. (2017). Comunicaciones y confianza: ¿información o identidad? El caso del sector vitivinícola chileno hacia el mercado chino. Palabra Clave, 20(2), 529-566. DOI: $10.5294 /$ pacla.2017.20.2.10

\section{Resumen}

Este artículo busca aportar a la discusión teórico-práctica sobre el rol de las comunicaciones corporativas en la construcción de confianza en el comercio global. Para ello, se utiliza el caso de estudio de la industria vitivinícola chilena y su comunicación hacia el mercado chino, y lo analiza desde dos aspectos centrales propios de la literatura: conocimiento e identidad. A través de la creación de una matriz basada en la semiótica y elaborada por los autores, se examinan en forma exploratoria seis sitios web corporativos de la industria. A partir de este caso de estudio, se entregan elementos que aportan a la discusión teórica, en el caso de la relación confianza y comunicación, así como a la discusión metodológica con la construcción de una matriz preliminar que releva los atributos del concepto de confianza.

\footnotetext{
* Este artículo se realizó gracias al financiamiento de Conicyt, Programa Fondecyt de Iniciación, Número 11140393 "Estrategias de Comunicación entre actores no estatales como factor de confianza en las relaciones internacionales: el caso de la República Popular China y Chile 2014-2017".

1 orcid.org/0000-0002-7788-4516. Pontificia Universidad Católica de Chile. Chile. claudialabarca@uc.cl

2 Pontificia Universidad Católica de Chile. Chile.rnrojas@uc.cl
} 
Se concluye que existen elementos cognitivos en la construcción de confianza entre organizaciones, pero también sobre un discurso de tipo moral e identitario y que hay escasa representación del enunciatario, lo cual debilita este último aspecto.

\section{Palabras clave}

Confianza; comunicación corporativa; engagement; Chile (Fuente: Tesauro de la Unesco).

\section{Communications and Trust: Information or Identity? The Case of the Chilean Wine Sector towards the Chinese Market}

\section{Abstract}

This article seeks to contribute to the theoretical-practical discussion on the role of corporate communications in building trust in global commerce. For this purpose, the case study of the Chilean wine industry and its communication towards the Chinese market is used, and it is analyzed from two central aspects of literature: knowledge and identity. Through the creation of a matrix based on semiotics and elaborated by the authors, six corporate websites of the industry are examined in exploratory form. From this case study, elements that contribute to the theoretical discussion are provided, for the case of the trust and communication relationship, as well as to the methodological discussion with the construction of a preliminary matrix that relieves the attributes of the concept of trust. It is concluded that there are cognitive elements in the construction of trust between organizations, but it is also about a moral and identity discourse and that there is little representation of the listener, which weakens this last aspect.

\section{Keywords}

Trust; corporate communication; engagement; Chile (Source: Unesco Thesaurus). 


\section{Comunicações e confiança: informação ou identidade? \\ 0 caso do setor vitivinícola chileno com o mercado chinês}

\section{Resumo}

Este artigo procura contribuir para a discussão teórico-prática sobre o papel das comunicações corporativas na construção de confiança no comércio global. Para isso, se utiliza o caso de estudo da indústria vitivinícola chilena e sua comunicação com o mercado chinês, e o analisa a partir de dois aspectos centrais próprios da literatura: conhecimento e identidade. Através da criação de uma matriz baseada na semiótica e elaborada pelos autores, se examinam em forma exploratória seis sites web corporativos da indústria. A partir deste caso de estudo se entregam elementos que contribuem para a discussão teórica, no caso da relação confiança e comunicação, assim como a discussão metodológica com a construção de uma matriz preliminar que releva os atributos do conceito de confiança. Conclui-se que existem elementos cognitivos na construção de confiança entre organizações, mas também sobre um discurso de tipo moral e identitário e que haja escassa representação do enunciatário, o que debilita este último aspecto.

\section{Palavras-chave}

Confiança; comunicação corporativa; engagement; Chile (Fonte: Tesauro da Unesco). 
A pesar del desarrollo de la conceptualización académica, de la confianza en las áreas organizacionales y de management (Kim, 2005) y de su importancia en cuanto resultado de la gestión de la comunicación (Tironi y Cavallo, 2007), esta aún no ha sido trabajada a fondo, en especial en la literatura hispana (Labarca, 2008). Aunque existen algunos casos excepcionales (Viñarás, 2013; Somma et al., 2016), el trabajo académico al respecto es aún incipiente. De hecho, la conceptualización de confianza es todavía confusa y se la homologa a la reputación corporativa (Carreras, Alloza y Carreras, 2013). Por ello, este artículo intenta llenar este vacío de la literatura y analizar, utilizando una matriz elaborada por los autores, los atributos de confianza que muestran las páginas web de la industria vitivinícola chilena tanto desde la perspectiva del enunciador (empresa-productos) como desde el enunciatario (mercado chino). Así, y empleando como metodología el análisis semiótico, se estudia cómo la gestión de la comunicación corporativa (en este caso cristalizada en las páginas web de la industria) contribuye, o no, a la formación de vínculos de confianza entre las empresas y sus respectivos stakeholders. Se elige este particular sector de la economía chilena debido a su importancia en la creación de imagen país (Felzenstein, 2008) y China por ser el primer socio comercial de Chile (Gobierno de Chile, Dirección General de Relaciones Económicas Internacionales, 2015), un país cuya economía se basa en la apertura de sus mercados y el comercio exterior (Labarca, 2015), así como por el contexto de interculturalidad que rodea este análisis. De esta forma, se intenta contribuir tanto teóricamente (estudio de los atributos de confianza que son posibles de construir a través de la comunicación corporativa) como al estudio de caso (industria vitivinícola chilena).

El artículo se estructura de la siguiente manera: primero, se realiza un análisis del concepto de confianza y comunicación corporativa como un instrumento para su gestión en cuanto creador de engagement entre las organizaciones y sus stakeholders. Luego, se presenta el modelo (matriz) de análisis y los resultados. Finalmente, se establecen las conclusiones.

\section{Confianza en la literatura}

Desde Adam Smith, Hume y Alexis de Tocqueville, hay consenso en la literatura académica en señalar los aportes de la confianza en las rela- 
ciones económico-sociales (Gambetta, 1988). La confianza fortalece la cooperación (Granovetter, 1985; Kramer, Brewer y Hanna, 1996; Hardin, 2002; Van de Ven y Smith, 2006), evita el comportamiento oportunista (Hardy, Phillips y Lawrence, 1998) y baja o elimina los costos de transacción (Coleman, 1988; Zak y Knack, 2001). Es también fundamental cuando no existe información necesaria para el buen funcionamiento del sistema social (Luhmann, 1979) o frente a debilidades contractuales (Coleman, 1990; Sollow, 2000; Cersosimo y Nistico, 2008), o institucionales (Child, 2001). Asimismo, se la ha asociado con crecimiento económico (Zak y Knack, 2001).

Sin embargo, no ocurre lo mismo en su definición y alcances. Ya sea desde el punto de vista macroeconómico (Fukuyama, 1995; Isham, Kelly y Ramaswamy, 2002; Inglehart et al., 2004) como interempresarial (Kramer y Cook, 2004; Bachmann, 2006; Top, Akdere y Tarcan, 2015; Ding, Au y Chiang, 2015), la confianza ha sido definida de múltiples maneras y desde distintas dimensiones (Kim, 2005). Desde la perspectiva del intercambio económico, uno de los mayores conflictos radica en la discusión sobre la naturaleza de la confianza y si esta es social o privada. Desde ahí se deriva la diferenciación entre confianza generalizada (confiar en el otro que no conozco) y confianza particular (concepto relacional entre partes claramente identificadas), aún no totalmente resuelta por la literatura (Uslaner, 2002). La primera se encuentra normalmente asociada al concepto de capital social (Coleman, 1988; Putnam, 2000), y es definida como una "disposición general a confiar", lo cual implica aspectos normativos e identitarios (Uslaner, 2002; Fukuyama, 1995). Es también llamada confianza moral, en cuanto se la concibe como

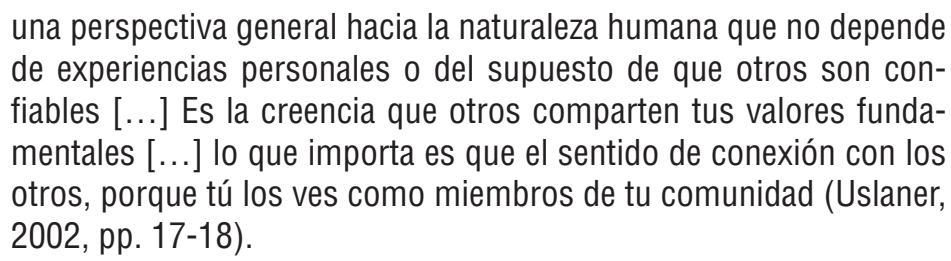

Desde esta perspectiva, la confianza social se da cuando existe convergencia de valores e identidades compartidas, lo cual se asocia a interacciones 
entre grupos con cierto grado de homogeneidad y mutuo conocimiento (Putnam, 2000, 2007).

La segunda es la confianza estratégica (Uslaner, 2002) o basada en el conocimiento (Hardin 2002; Yamagishi y Yamagishi, 1994; Yamagishi, 2011), que pertenece al ámbito privado en cuanto, como señala Hardin (2002), se la concibe como un acuerdo entre tres partes: A confía en B para hacer $\mathrm{X}$ y por tanto se la puede definir como las expectativas que A tiene con respecto a B. Esto tiene una doble implicación. Por un lado, la confianza se va construyendo de acuerdo con la interrelación entre las partes, dado que depende de factores, como interacción, experiencia y reputación (Yamagishi, 2011; Putnam, 2002). Por otro, esta perspectiva está normalmente asociada a visiones racionalistas y, desde el punto de vista sociológico, a las teorías de cooperación (Axelrod, 1984). Es este último punto de vista el que se ha asociado a la interacción entre compañías y a la acción comunicacional, aunque existen modelos que combinan ambas propuestas. Dietz y Gillespie (2011), por ejemplo, propone un modelo de confianza interorganizacional, en el cual los atributos de confianza son estos: habilidad (competencia técnica), benevolencia (motivos e intereses) e integridad (honestidad y tratamiento justo). No incluye, sin embargo, el tema identitario, aunque sí rescata algunos elementos de la conceptualización de la confianza moralista propuesta por Uslaner (2002).

\section{Comunicación corporativa como instrumento de creaión de confianza}

Las comunicaciones corporativas cada vez más se conciben como una función que apunta al relacionamiento de las organizaciones con el entorno y a lograr engagement con sus principales públicos o stakeholders (Capriotti, 2009; Gutiérrez-García, 2010; Carreras, Alloza y Carreras, 2013; Cornelissen, 2011; Van Riel y Fombrun, 2007; Freeman, 1984, 2010). Esta vinculación se entiende como vital para sustentar a largo plazo la existencia y el éxito de las organizaciones (Capriotti, 2009; Cornelissen, 2011; Gutiérrez-García, 2010; Van Riel y Fombrun, 2007). Desde la perspectiva del relacionamiento, algunos autores definen la confianza como el deber ser de las comunicaciones en las organizaciones. Tironi y Cavallo (2007) 
definen como el fin último de la comunicación corporativa "proyectar la identidad de las organizaciones en una imagen que suscite confianza en su entorno relevante y adhesión en su público objetivo" (p. 27), mientras que Swift (2001) explica el objetivo de las comunicaciones en las empresas como "buscar el establecimiento de la confianza en sus relaciones con los stakeholders" (p. 16).

Desde el punto de vista teórico, la confianza se asocia a la comunicación, ya que se sindica a la primera como "resultado de un proceso comunicativo" (Hardy, Phillips y Lawrence, 1998, p. 71), que, cuando se ve debilitado - por problemas de comunicación, lenguaje o entendimiento-, trae consecuencias en la construcción de confianza, en especial en intercambios transnacionales (Child, 1998).

De este modo, como argumentan Valentini y Kruckeberg (2011), la sociedad actual, caracterizada como "hipercompleja, postmoderna, en la cual se reclama que el rol de las relaciones públicas, ${ }^{3}$ es el de fortalecer las interacciones de los sistemas a través de la creación de confianza" (p.91), y en el cual coexisten distancias culturales que dificultan aquella.

Para ello, la comunicación corporativa cuenta con herramientas que ayudan a fortalecer dichas interacciones. Una de estas es internet. Como apuntan Capriotti y Moreno (2007), diversos autores ya han recalcado la importancia de la internet como herramienta esencial de las comunicación corporativa, en especial en una era donde la interactividad es fundamental en el relacionamiento entre la organización y sus stakeholders, tanto como proveedor de información como generador de relacionamiento. Más aún, previos trabajos ya han demostrado que el uso de sitios web corporativos aumenta la confianza de los stakeholders en las compañías (Hong y Rim, 2010).

Por tanto, se buscan examinar las estrategias de comunicación corporativas visibles en los sitios web para evaluar si estas poseen elementos que apunten al engagement (relacionamiento) con sus stakeholders y así a la

3 Como en muchos trabajos anteriores, en este artículo, se igualan las conceptualizaciones estadounidenses de relaciones públicas a la de comunicación estratégica usada en América Latina. 
creación de confianza. Específicamente, los elementos asociados a la identidad y a lo cognitivo (confianza moral y estratégica descrita en los párrafos anteriores). Así, se analizan sitios web corporativos, ya que, como hemos propuesto en trabajos anteriores (Labarca y Rojas, 2015), se consideran el mejor indicador de relacionamiento y construcción del vínculo con los stakeholders en un contexto global. Siguiendo a Maynard y Tian (2004), los sitios web constituyen la herramienta básica para estrategias de comunicación corporativa y, por tanto, el mejor canal que tiene una firma para comunicarse con un amplio rango de stakeholders a bajo costo y con un alto impacto reputacional. Esto es específicamente válido para el caso de estudio donde la distancia física, la diferencia de uso de horarios y otros elementos consignados en trabajos previos (Labarca, 2015) dificultan el uso de otros canales comunicativos.

Se elige el caso de estudio entre China y Chile debido a la distancia cultural percibida entre las partes y a los escasos niveles de confianza consignados privados, debido a dos variables de confianza: conocimiento e identificación mutua que quieren ser estudiadas y que se encuentran ausentes en la relación interempresarial (Labarca, 2012). Dentro de las empresas exportadoras se elige a la industria vitivinícola por ser relevantes en la creación de imagen de marca (Felzenstein, 2008) en el caso chileno y por su explosivo aumento en las relaciones comerciales con China. Asimismo, se escoge porque, tal como lo explicara un importante ejecutivo del sector: "Chile ha construido su reputación de vinos buenos pero no costosos y tenemos que cambiar esta percepción” (Dowling, 2012), por tanto, una identidad corporativa que lo encasilla en una determinada segmentación de mercado. Esto dificulta la generación de engagement y lazos de mejor nivel que puedan significar darle un valor agregado a la producción vitivinícola local. A pesar de ello, existen fuertes ventas en el mercado que aquí se tratan: a julio de 2015, el vino chileno embotellado creció $122.47 \%$ en volumen y $87.64 \%$ en valor respecto del mismo mes de 2014 (Economía y Negocios, 2015).

Finalmente, es importante destacar que se ha establecido que en situaciones interculturales - como el caso que aquí se explora- la confianza y la comunicación son dos factores críticos que determinan el éxito o 
el fracaso de cooperación transnacional (Ochieng y Price, 2010). Como explican Valentini y Kruckeberg (2007), "en nuestra sociedad compleja y multifacética, las organizaciones y las personas están afectadas por la globalización hasta el punto de que no pueden pensarse como mono o biculturales" (p. 92), por lo que se espera también contribuir en este ámbito.

\section{Metodología de análisis}

El análisis se efectúa desde una perspectiva cualitativa e interpretativa (Denzin y Lincon, 2000), que entiende la realidad con un "un significado inherente" (Schwandt, 2000, 189), mediante un análisis de discurso, de la manera de examinar los contenidos y la forma como las organizaciones en estudio transmiten su mensaje hacia el mercado chino. Esto tanto desde la perspectiva del enunciador como también desde el objeto al que hacen referencia (en este caso sus stakeholders chinos). Entendemos el discurso como espacios de intersubjetividad (Benveniste, 1977; Maingueneau, 1980; Peñamarín, 1997), en el cual existe un diálogo entre el emisor del mensaje (yo-locutor: empresas chilenas en estudio) que instala delante suyo un túalocucionario (stakeholders chinos), que es su destino, y se produce así un diálogo entre ambas partes que puede ser analizado desde el punto de vista del discurso (Gómez, 2009).

Esta perspectiva nos permite explorar la re-presentación del enunciador, cómo construye su identidad y cómo permite identificar la imagen pre-concebida del destinatario (Gómez, 2009). Analizar los discursos implica "enfocar todo ese ámbito de lenguajes, normas y significaciones (que se estiman) compartidos” (Peñamarín, 1997, pp. 146-147).

Sin embargo, este proyecto se enmarca en relaciones globales, en el que ambos actores se entienden con una distancia cultural preconcebida (Labarca, 2015) y, por ende, sin necesariamente compartir las mismas significaciones (Rodrigo, 1999). Se proponen tres matrices de análisis que se refieren tanto al enunciador como al enunciatario. Su construcción se basa en una aproximación semiótica, considerada como una metodología válida para la descripción e interpretación de textos-discursos (Abril, 1994), y en los marcos de sentido, conceptualización propuesta por Lakoff (2004), 
quien entiende estos marcos como "estructuras mentales que moldean la forma en que vemos el mundo” (p.XV) y que están determinados desde el lenguaje, pero también desde el entorno que los rodea.

\section{Selección de la muestra}

Se utilizó un muestreo por criterio (Patton, 1990), con el fin de elegir aquellos casos que aportaran mayor riqueza a la investigación sobre una base de datos de exportadores chilenos (número total universo: 360; total de viñas con sitio web: 90), construida sobre información oficial y pública extraída del sitio web de ProChile en 2013. ${ }^{4}$

La tabla 1 resume los criterios de selección de las empresas seleccionadas para este artículo:

\section{Tabla 1. Criterios utilizados en la selección de la muestra de análisis}

\begin{tabular}{|c|c|c|}
\hline Clasificación & Atributo & Valor \\
\hline $\begin{array}{c}\text { Representatividad y relevancia de } \\
\text { exportaciones en el rubro (viñas) }\end{array}$ & $\begin{array}{c}\text { Volumen de transacciones } \\
\text { realizadas a China }\end{array}$ & Unidades transadas por año \\
\hline $\begin{array}{c}\text { Desarrollo en curso de un plan o } \\
\text { estrategia de comunicación hacia el } \\
\text { mercado chino }\end{array}$ & $\begin{array}{c}\text { Existencia explícita de un plan } \\
\text { estrategia de comunicación } \\
\text { dirigida a China }\end{array}$ & $\begin{array}{c}\text { Opción de seleccionar el idioma chino en el } \\
\text { ingreso en el sitio }\end{array}$ \\
\cline { 2 - 3 } & $\begin{array}{c}\text { Existribuidores dedicados dolo a trabajar con } \\
\text { China }\end{array}$ \\
\hline $\begin{array}{c}\text { Representación del mercado chino } \\
\text { de forma explícita en la web }\end{array}$ & $\begin{array}{c}\text { Alusión directa a China en la la } \\
\text { comunicación y el material } \\
\text { audiovisual }\end{array}$ & $\begin{array}{c}\text { Existencia de videos o imágenes alusivas a } \\
\text { China }\end{array}$ \\
\cline { 2 - 3 } & & $\begin{array}{c}\text { Existencia de noticias alusivas a la relación de } \\
\text { la empresa con China }\end{array}$ \\
\hline
\end{tabular}

Fuente: elaboración propia.

Primero, se visitaron los sitios web de las 90 viñas presentes en la base de datos de ProChile, lo cual permitió identificar ciertos patrones relacionados con estrategias comunicativas hacia el mercado chino. Una vez identificadas estas estrategias, se hizo un cruce de los sitios más ricos en contenido con el detalle del volumen de exportación de las viñas, para lograr identi-

4 ProChile es la agencia gubernamental chilena de fomento a las exportaciones. Sitio web: www.prochile.cl 
ficar una muestra, que, además de ser interesante respecto de la construcción del sitio web, cumpliese con los criterios que permitieran un análisis más enriquecido dentro del mercado vinícola chileno. Como se ha explicado, este artículo tiene una orientación cualitativa, que no intenta generalizar resultados, sino solo contribuir desde la perspectiva de un caso de estudio a la gestión de la comunicación y su relación con la generación de confianza entre la organización y los stakeholders.

Una vez definidos los parámetros buscados, se realizó la selección de la muestra con 10 empresas que presentaron los atributos previamente definidos. De estas, se escogen 6 para su análisis en profundidad, tal como lo sugiere Geert Hofstede (s. f.), lo cual permite la riqueza del análisis. Solo 2 no tienen versión en idioma chino de sus sitios, y todas tienen versión en inglés.

\section{Confección de las matrices de análisis}

La construcción de las matrices de análisis y, por ende, las categorías que aquí se presentan surgen desde dos ámbitos. Por un lado, emergen de la observación profunda de los 10 primeros sitios web donde se rescatan los elementos más repetitivos (por ejemplo presentación del producto) y que se encuentran principalmente en la primera columna. En una segunda instancia, tanto la segunda como la tercera columna tienen una base más teórica, en la que se rescatan elementos basados en la revisión de la literatura sobre confianza. Así, por ejemplo, el atributo familia o historia corresponde a un intento de generar identidad con el destinatario (confianza que hemos denominado moral siguiendo a Uslaner [2002]), mientras que la idea de premios o infraestructura y procesos se engarza más con la idea de competencia o habilidad técnica subrayada por Dietz y Gillespie (2011) y se relaciona con una mirada más racionalista/cognitiva de los factores que determinan la confianza. Por tanto, esta propuesta es una clasificación de las estrategias semánticas del discurso contenido en los sitios web analizados y contempla tanto su material visual como textual. Siguiendo a Verón (1984), se propone imagen del enunciador, que corresponde al imaginario con que la compañía quiere asociarse; enunciación, que es el modo en que se describen y presentan los diferentes elementos propios de las compañías 
consideradas en nuestro análisis; y enunciado, que en este caso son los diferentes elementos propios de las compañías que se muestran en sus sitios web mediante texto e imágenes.

La matriz número uno explora los elementos que la organización utiliza para darse a conocer al mercado como organización desde estas tres perspectivas (tabla 2).

\section{Tabla 2. Matriz de análisis 1: imagen de la organización}

\begin{tabular}{|c|c|c|}
\hline \multicolumn{3}{|c|}{ Imagen de la organización (enunciador) } \\
\hline Imagen del enunciador & Enunciación & Enunciado \\
\hline \multirow{4}{*}{$\begin{array}{l}\text { Integrantes (cómo se } \\
\text { refiere la organización } \\
\text { a sus miembros: } \\
\text { trabajadores, ejecutivos) }\end{array}$} & \multirow{4}{*}{$\begin{array}{l}\text { Referencias textuales } \\
\text { de denominación a } \\
\text { los miembros de la } \\
\text { organización }\end{array}$} & Familia \\
\hline & & Nuestro equipo (directorio) \\
\hline & & Equipo humano (trabajadores) \\
\hline & & Individuo protagonista (enólogo, fundador, director, etc.) \\
\hline \multirow[b]{2}{*}{ Infraestructura y procesos } & \multirow{2}{*}{$\begin{array}{l}\text { Calidad tecnológica } \\
\text { que destacan en } \\
\text { sus implementos y } \\
\text { dependencias }\end{array}$} & Indumentaria tradicional, técnicas e infraestructura heredada \\
\hline & & $\begin{array}{c}\text { Tecnología de punta, modernidad en técnicas e } \\
\text { infraestructura }\end{array}$ \\
\hline \multirow{4}{*}{ Cualidad destacada } & \multirow{4}{*}{$\begin{array}{l}\text { Aspecto central en el que } \\
\text { basan su confiabilidad }\end{array}$} & Historia y tradición \\
\hline & & Reconocimientos y premios \\
\hline & & $\begin{array}{l}\text { Sustentabilidad (conciencia y responsabilidad social y } \\
\text { medioambiental) }\end{array}$ \\
\hline & & Información financiera \\
\hline \multirow{4}{*}{$\begin{array}{l}\text { Ubicación e identidad } \\
\text { chilena }\end{array}$} & \multirow{4}{*}{$\begin{array}{c}\text { Elementos que denotan } \\
\text { identidad y pertenencia } \\
\text { a Chile }\end{array}$} & Información de Chile y sus valles \\
\hline & & Cómo llegar (mapa e indicaciones de cómo llegar a la viña) \\
\hline & & Fotografías y material audiovisual de sus viñedos \\
\hline & & Paseo virtual (tour por los valles de la viña en Chile) \\
\hline
\end{tabular}

Fuente: elaboración propia.

La segunda matriz permite analizar al producto (también como enunciador) con categorías específicas de este y distintas de las construidas en la matriz anterior (tabla 3). 
La tabla 4 enseña las categorías de análisis de cómo la organización crea una imagen del enunciatario, los stakeholders chinos (enunciatarios, recipientes de la comunicación).

\section{Tabla 3. Matriz de análisis 2: imagen del producto}

\begin{tabular}{|c|c|c|}
\hline \multicolumn{3}{|c|}{ Imagen del producto (enunciador) } \\
\hline Imagen del enunciador & Enunciación & Enunciado \\
\hline \multirow{3}{*}{ Presentación } & \multirow{3}{*}{$\begin{array}{l}\text { Modo en que introduce el } \\
\text { producto }\end{array}$} & Fichas descriptivas \\
\hline & & Premios que ha ganado \\
\hline & & Videos de cómo se fabrica \\
\hline \multirow{5}{*}{$\begin{array}{l}\text { Valor/es centrales del } \\
\text { producto }\end{array}$} & \multirow{5}{*}{$\begin{array}{c}\text { Valores explícitos } \\
\text { (textuales) que se destacan } \\
\text { de sus vinos }\end{array}$} & Calidad \\
\hline & & Elegancia \\
\hline & & Familiar (que genera instancias de compartir) \\
\hline & & Fruto de un trabajo en equipo \\
\hline & & $\begin{array}{l}\text { Satisfactorio (vino pensado en satisfacer a los clientes de la } \\
\text { marca) }\end{array}$ \\
\hline \multirow{2}{*}{ Protagonismo } & \multirow{2}{*}{$\begin{array}{l}\text { Qué lugar ocupan en el } \\
\text { sitio los vinos }\end{array}$} & Poseen una pestaña principal dedicada a ellos \\
\hline & & Aparecen solo al desplegar otra pestaña de las principales \\
\hline
\end{tabular}

Fuente: elaboración propia.

\section{Tabla 4. Matriz de análisis 3: imagen del mercado chino}

\begin{tabular}{|c|c|c|}
\hline \multicolumn{3}{|c|}{ Imagen del enunciatario } \\
\hline Imagen del Enunciatario & Enunciación & Enunciado \\
\hline \multirow{3}{*}{$\begin{array}{l}\text { Modo de convivencia con } \\
\text { representantes del mercado } \\
\text { chino (relacionamiento con } \\
\text { el stakeholder chino) }\end{array}$} & \multirow{3}{*}{$\begin{array}{l}\text { Tipo de instancias en las } \\
\text { que se da la convivencia }\end{array}$} & Reuniones formales \\
\hline & & Exposiciones y muestras \\
\hline & & Reuniones informales (comidas, tours, etc.) \\
\hline \multirow[t]{2}{*}{ Visión del mercado } & \multirow{2}{*}{$\begin{array}{l}\text { Cómo se refiere al } \\
\text { mercado chino respecto } \\
\text { de los negocios }\end{array}$} & $\begin{array}{l}\text { Territorio en proceso de conquista (marca que se establece, } \\
\text { que gana terreno) }\end{array}$ \\
\hline & & Territorio ya conquistado (marca establecida) \\
\hline \multirow{5}{*}{ Contacto } & \multirow{5}{*}{$\begin{array}{l}\text { Modalidad de contacto } \\
\text { que ofrece la organización } \\
\text { al interesado chino }\end{array}$} & Contacto con gerente (comercial) \\
\hline & & $\begin{array}{c}\text { Contacto con agente dedicado a la comunicación } \\
\text { internacional general de la empresa }\end{array}$ \\
\hline & & Contacto \\
\hline & & Contacto con agente especializado en el mercado chino \\
\hline & & Contacto con oficina ubicada en China \\
\hline \multirow{3}{*}{ Acceso (idioma) } & \multirow{3}{*}{$\begin{array}{l}\text { Modo en que se presenta } \\
\text { la página (idioma) }\end{array}$} & Copia del sitio en castellano traducido al inglés \\
\hline & & Copia del sitio en castellano traducida al chino \\
\hline & & Sitio diferente del original (castellano) realizado en chino \\
\hline
\end{tabular}

Fuente: elaboración propia. 


\section{Resultados}

A continuación se presentan los resultados basados en las tres matrices anteriores propuestas.

\section{Imagen de la organización: composición interna de la compañía}

Las imágenes de sus propios integrantes que proyectan las compañías vitivinícolas chilenas aquí analizadas hacia sus stakeholders presentan dos tipos predominantes. Una es la imagen individual y la otra colaborativa. La primera basa su imagen en la figura de un líder o líderes caracterizados individualmente y la otra según líderes colaborativos con un equipo que los respalda. Respecto del tipo individual, los líderes que soportan la imagen de la composición interna de la compañía corresponden a fundadores, directorio o enólogos. En el caso de figurar como líder el fundador de la compañía, la imagen y las descripciones muestran una familia poderosa, tradicional e influyente nacional (ver el caso típico en http://www.errazuriz.com/quienes-somos/fundador/). Se privilegian los orígenes y el liderazgo (identidad) en vez de la habilidad del líder contemporáneo.

En el caso del liderazgo representado por el enólogo de la compañía, la fotografía y descripción muestran la imagen moderna del éxito basado en la calidad de su trabajo, constancia y profesionalismo (ver, por ejemplo, http://www.vinamaipo.com/enologo/). Finalmente, en el caso de figurar como líder el directorio (o alguno de sus integrantes) de la compañía, la descripción muestra capacidad y cualificación de los profesionales a cargo, sin imagen que muestre a los profesionales aludidos ni a su equipo.

La imagen colaborativa de la composición interna que las compañías proyectan en sus sitios web corresponde a un líder acompañado por un equipo de trabajo indispensable para el proceso productivo. Los líderes (familias, directivos o enólogos) son tales gracias a la colaboración del equipo de trabajo, quienes son representados en la figura de los directivos y los trabajadores. En el caso de los primeros, su descripción corresponde a nombre y cargo, sin mencionar sus aptitudes y cualificaciones profesionales, 
pero son representados en forma individual (ver, por ejemplo, los directivos de Viña Garcés Silva en http://www.vgs.cl/index.php?accion=equipo).

En el caso de los trabajadores de la viña, se los muestra en imágenes, pero no se les identifica individualmente. Estos aparecen en un trabajo colectivo y cooperativo. Otras resaltan al trabajador desde la perspectiva individual. Un buen ejemplo aparece en la figura 1.

Son muchos los factores que influyen en la calidad de un vino y uno de los más importantes es la dedicación que los trabajadores de la viña ponen en su trabajo. Nuestra gente ha nacido en estas tierras, por muchas generaciones, por eso conocen mejor que nadie sus secretos, los que forman parte también de la magia de Amayna.

\section{Figura 1. Trabajadores de viña Garcés Silva}

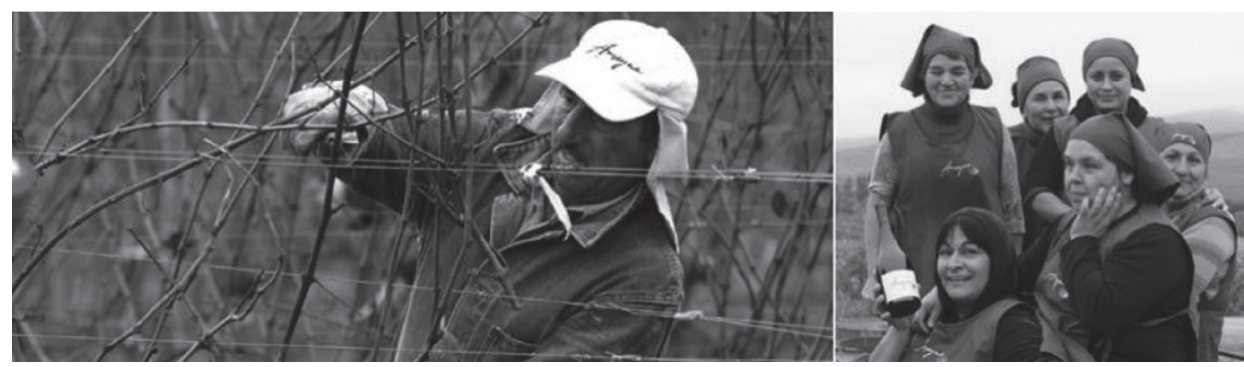

Fuente: http://www.vgs.cl/index.php?accion=equipo

Se considera el rol de cada estamento del equipo de la compañía como pieza relevante en el proceso de producción de los vinos, lo cual proyecta una imagen de colaboración.

\section{Imagen de la organización: infraestructura y procesos}

La imagen proyectada por las vitivinícolas chilenas analizadas respecto de su infraestructura y procesos gira en torno a 1) modernidad y tecnología y 2) tradición y calidad humana. En el primer caso, se proyecta una imagen de modernización de los procesos productivos, principalmente a través de la exposición de las maquinarias especializadas y novedosas en el rubro, por ejemplo: 
Vinificación: la decantación por gravedad implica que en ninguna etapa del proceso se utilizan bombas, lo cual determina una serie de ventajas: mayor higiene, menor maltrato a jugos y vinos, menor astringencia, mayor elegancia.

Sala de barricas: cuenta con un moderno sistema que controla la temperatura y la humedad, lo cual permite mantener y mejorar la calidad del vino que está envejeciendo en las barricas.

\section{Figura 2A. Sala de barricas viña Garcés Silva Figura 2B. Trabajadoras seleccionando uvas en la viña}

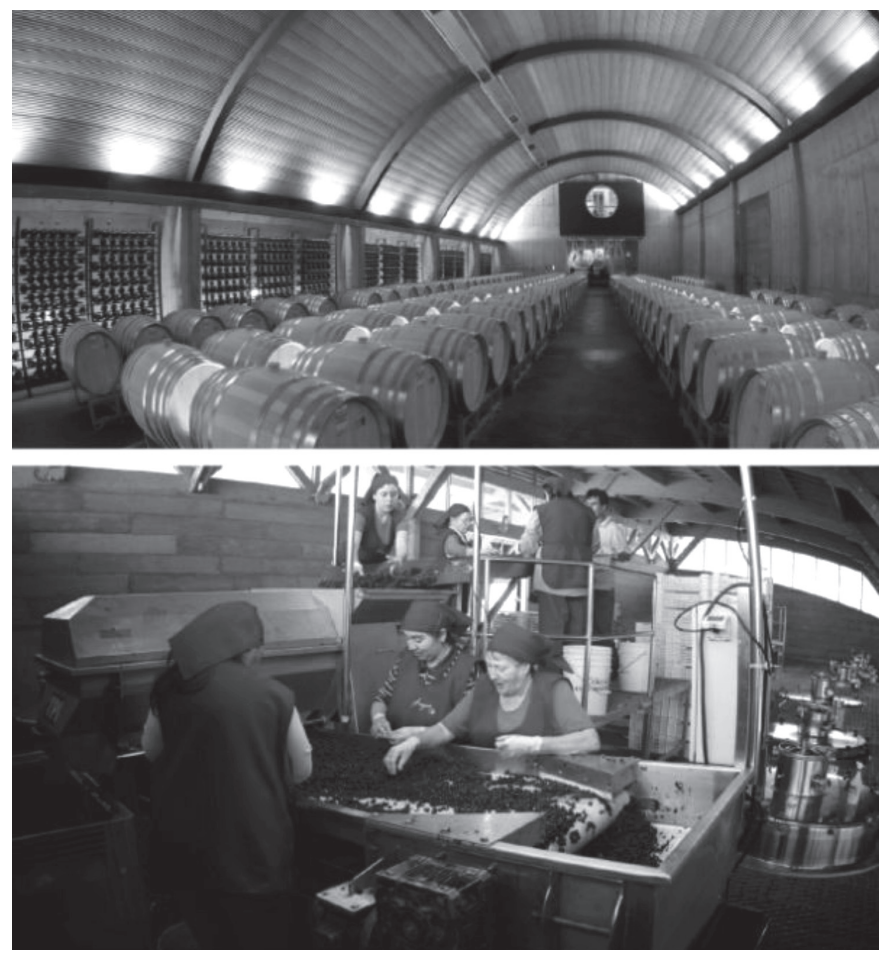

Fuente: http://www.vgs.cl/index.php?accion=bodega

En las figuras 2A y 2B se aprecia la presencia de la infraestructura, la maquinaria y los operadores involucrados en el proceso productivo, y se destacan en el texto las ventajas del proceso técnico utilizado en la producción de los vinos. 
En el caso de una imagen inclinada hacia la tradición y calidad humana, los protagonistas son las personas que trabajan en la viña. Nótese en el texto (acompañado de una figura humana catando el vino):

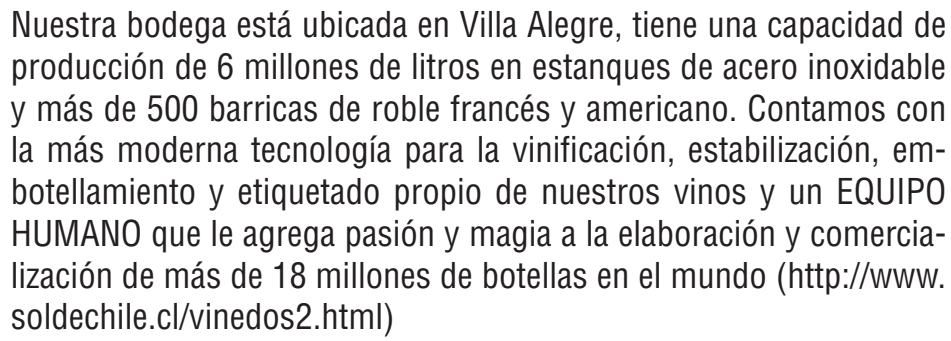

Aunque se mencione igualmente la tecnología moderna usada en los procesos productivos, es el equipo de personas — notamos en la imagen vestimenta corporativa de la compañía - el que imprime al producto la cualidad que lo distingue, por lo que figura como factor preponderante en el proceso.

\section{Imagen de la organización: confiabilidad de la compañía}

La imagen de confiabilidad que proyectan las compañías exportadoras de vinos se basa en 1) datos verificables que justifican la competitividad en el mercado y 2) valores morales que se asocian a un mejor producto. Respecto del punto uno, en los sitios web de las viñas analizadas, aparecen secciones relacionadas a instancias formales de reconocimiento nacional e internacional de la calidad de los productos ofrecidos y la experticia enológica que la sustenta, básicamente a través de premios y distinciones de la industria, que posicionan a las viñas en el mercado de los vinos como una compañía confiable por sus premios ganados (ver http://www.errazuriz.com/errazuriz-obtiene-destacados-puntajes-en-descorchados-2016/ o http://www.vinamaipo.com/reconocimientos/).

Respecto del punto dos, las vitivinícolas muestran una imagen de confiabilidad basada en valores morales asociados a un proceso productivo responsable con el medioambiente y los trabajadores (ver, por ejemplo: http://sustentabilidad.santarita.cl/; http://www.casasdeltoqui.cl/eco amigable.html o http://www.vgs.cl/index.php?accion=sustentabilidad). 
La consideración del cuidado del medioambiente y de la salud de los trabajadores es relacionada con un aumento en calidad del producto que se comercializa en la compañía. Asimismo, valores como la excelencia, la innovación y las características naturales de Chile se muestran a modo de vinculación con el contexto local en que se desarrolla, en este sentido de construcción de identidad asociada a la confiabilidad moral (ver Uvas de Viña Maipo: http:// www.vinamaipo.com/enologo/proyecto-enologico/).

La transparencia es otro valor moral que aparece en los sitios web oficiales de las viñas analizadas. La existencia de documentos descargables con informes que exponen abiertamente la información financiera de la organización, las cifras de dinero transados y el porcentaje de participación de otras firmas son parte de los contenidos de los llamados "Sustentability Report: Viña Santa Rita and Affiliates". 5 De esta manera, la compañía proyecta una imagen de confianza basada en valores moralmente legitimados.

\section{Imagen de la organización: identidad chilena}

Las viñas denotan su pertenencia a Chile mediante material audiovisual que introduce ciertas características geográficas y turísticas acerca de la viña, dónde se emplaza y cómo funciona, y en él aprecian variadas imágenes del país (ver, por ejemplo, el caso de Viña Santa Rita, en www.santarita.com).

Hay compañías que proyectan su pertenencia a Chile hacia el mercado chino en específico, y asocian su valor cultural y turístico con sus procesos productivos y, en última instancia, con su producto. Hay otras viñas que destacan su chilenidad a través del ofrecimiento de servicios turísticos. Mostrar las instalaciones de la viña como un producto turístico, al cual se tiene acceso virtual - y eventualmente de manera física — proyecta cercanía y abre vías alternativas de contacto con sus clientes (http://www.santarita.com/chile/tour/).

En otros casos, la construcción de la identidad chilena se basa en la visibilidad de costumbres y la cultura asociada a la nación del país. Vestimentas y arquitectura tradicional, incluso decoraciones domésticas de marcada

5 http://www.santarita.com/international/files/2013/09/Sustainability-Report-2011-eng.pdf 
estética local (ver, por ejemplo, las diferentes fotografías donde se muestra el huaso tradicional chileno y la arquitectura local en http://www.deaguirre.cl/galeria/)

De este modo, la compañía construye identidad chilena que proyecta hacia sus stakeholders en el sitio web, mediante la exposición de distintos aspectos de pertenencia al país que muestra basada en texto imagen y material audiovisual. Así, vincula sus procesos productivos y productos no solo con el entorno, sino también con la cultura del país, y les da un contexto reconocible y particular que a la vez los diferencia de la competencia y los hace partícipes de un contexto local compartido culturalmente en la nación.

\section{El producto: presentación}

La presentación del principal producto de las compañías vitivinícolas, sus vinos, ofrece distintos recursos mediante los cuales se los puede conocer fácilmente navegando en el sitio web. Por lo general, se encuentra en el menú principal un acceso rápido y vistoso al catálogo de vinos, donde se puede apreciar en detalle las características de cada uno: los catálogos son interactivos y ofrecen variada información sobre los productos. Dicha información va desde aspectos técnicos especializados, hasta recomendaciones de recetas para acompañar el consumo de los vinos, lo cual abarca distintos niveles de posibles compradores.

Una primera aproximación es la de mostrar el producto en detalle. Normalmente se acompaña de una descripción enológica, recomendaciones de comidas para acompañarlo, incluso la temperatura óptima para su consumo, lo cual apunta a un consumidor sofisticado y con altos niveles de interés (ver, por ejemplo, http://www.vgs.cl/index. php? accion=vinoAmayna_suavBlancBarrelFerme). En otros, la sugerencia es más directa. Se acompaña la fotografía del producto con los frutos con los cuales se le relaciona enológicamente y una fotografía del plato de comida sugerido para su consumo. Incluso se tiene acceso a la receta para la preparación del plato sugerido (un ejemplo está en http://www.vinamaipo.com/vinos/vitral/cabernet-sauvignon/). Finalmente, hay también fichas técnicas, donde puede encontrarse información detallada sobre 
su consumo, pero, además, sobre su proceso de producción —la "vinificación”-, que lo distingue de otros productos elaborados mediante procesos diferentes (http://www.santarita.com/chile/nuestros-vinos/ casa-real/cabernet-sauvignon/). Esta información se orienta a compradores especializados en los aspectos técnicos de la elaboración de vinos. Diremos, entonces, que la presentación de los productos está basada en proveer una gran cantidad de información y, asimismo, diseñada para captar la atención de una amplia gama de posibles compradores, con intereses y aptitudes distintas.

\section{El producto: puesta en valor}

La puesta en valor de los vinos se realiza mediante la vinculación con características que exceden los atributos de su consumo y modo de producción. Al igual que en la organización, se los relaciona con valores morales con los que se identifica la compañía, como calidad, medio ambiente y seguridad laboral. Así, la elaboración de vinos de "alta calidad" se vincula con los valores de responsabilidad con el entorno, con los cuales se identifica la compañía como organización. Por otro lado, los atributos con que se vinculan los vinos giran en torno al disfrute de un producto exclusivo y único (ver http://www.vgs.cl/index.php?accion=vinoAmayna), que apunta hacia la distinción y exclusividad, no solo por las cualidades propias del vino, sino también por quién, dónde y cómo es elaborado.

\section{Imagen del enunciatario: convivencia}

Las instancias de convivencia presencial entre los representantes de las compañías chilenas con sus contrapartes chinas corresponden principalmente a instancias formales donde se celebran encuentros, acuerdos o exposiciones de productos. Existen dos tipos de convivencia que tienen distintos grados de formalidad. Las figuras 3 y 4 presentan una relación más cercana/lúdica. La presencia de los representantes chinos de la compañía asiática es ampliamente visible y se los muestra en instancia de distensión, sin embargo, no sale del marco de celebraciones formales entre compañías para la concreción de acuerdos y convenios. Asimismo, la figura 3 muestra cercanía física y cierta informalidad en los participantes del entorno formal. 


\section{Figura 3. Encuentro de promoción en China}

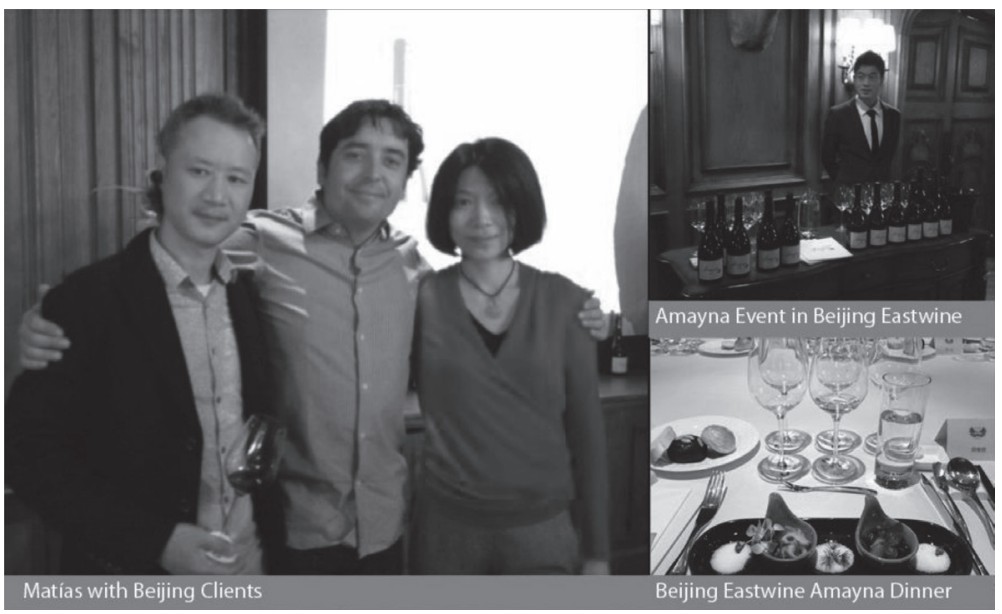

Fuente: http://www.vgs.cl/index.php?accion=noticias

\section{Figura 4. Encuentro con distribuidor en China}

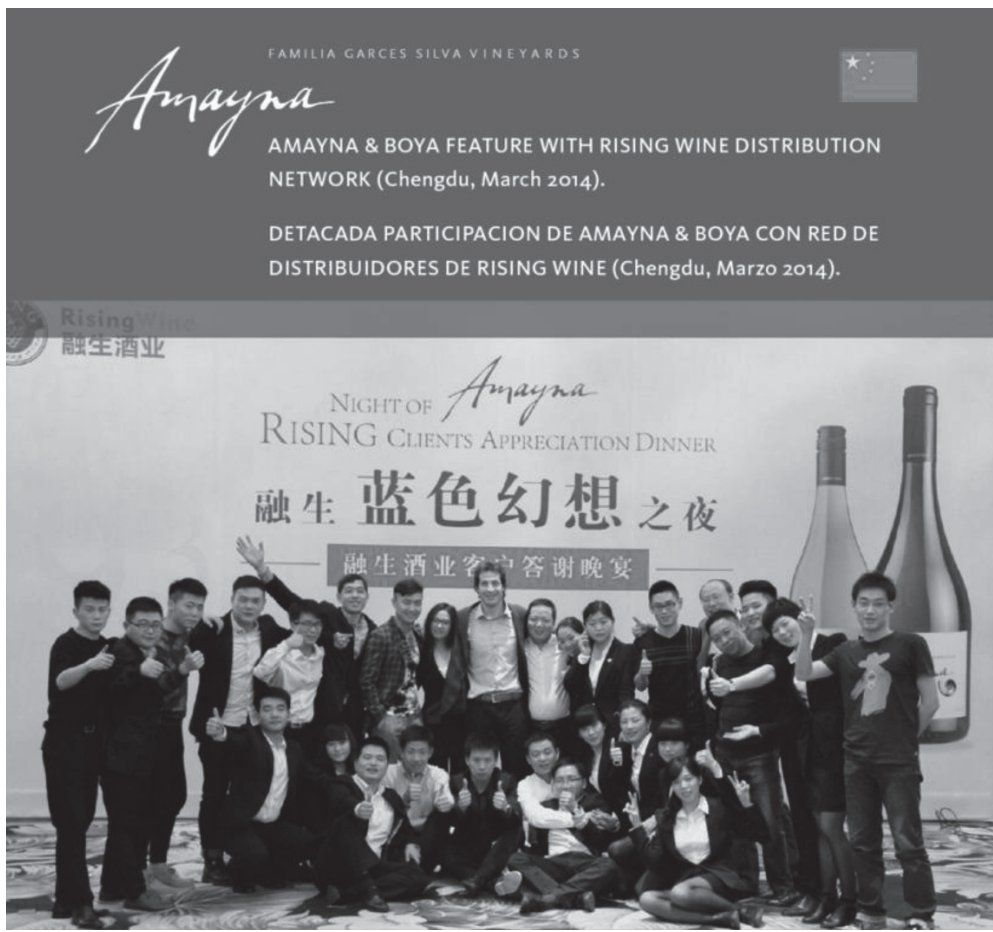

Fuente: http://www.vgs.cl/index.php?accion=noticias 
La figura 5 encarna la generalidad de las representaciones encontradas a lo largo del análisis de las páginas web, de corte más formal e institucionalizado. Se aprecia la celebración de un acuerdo con la compañía COFCO, una de las empresas estatales más importantes de China, la que se muestra como una gran oportunidad comercial para la firma chilena y con presencia de sus representantes.

\section{Figura 5. Encuentro para acuerdo en China}

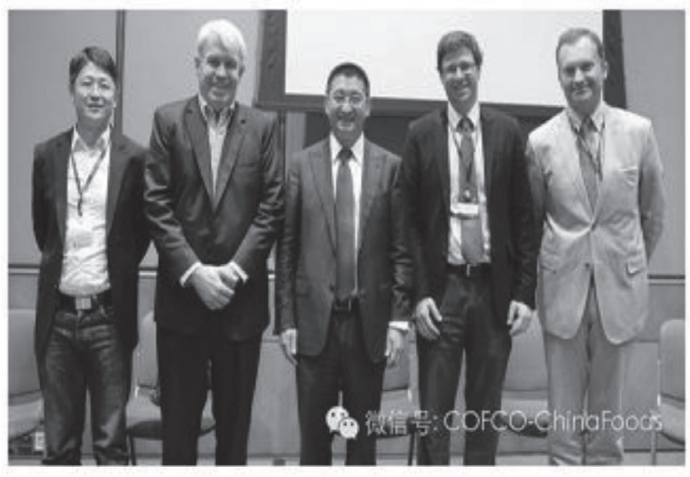

\section{VIÑA MAIPO \& COFCO EN CHINA}

Es un orgullo anunciar que Viña Maipo formó un nuevo acuerdo de distribución con la prestigiosa empresa "COFCO Wine \& Spirits Co". Esto permite acceder a las amplias redes de distribución de un importante y gran mercado como China, posicionando sólidamente todo el portafolio de Viña Maipo.

Fuente: http://www.vinamaipo.com/vina-maipo-cofco-en-china-2/

Otra instancia de relacionamiento son las visitas de empresarios chinos a Chile (http://www.santarita.com/espanol/noticias/press-releases/ santa-rita-premio-con-un-viaje-a-chile-a-los-mejores-vendedores-de-medalla-real/), que incluyen degustaciones, comidas y entretenimiento, donde se comparten los vinos más destacados de la compañía chilena en un contexto corporativo formal.

Por tanto, en las interacciones, observamos el predominio de una convivencia de tipo formal: celebración de acuerdos o encuentros entre compañías asociadas a la producción y comercialización del vino. Esto permite una identificación de las compañías analizadas con una imagen de paridad y compromiso creciente con sus stakeholders chinos, que proyectan una imagen de comunidad con ellos.

A pesar de ello, hemos querido también ejemplificar un caso desviado, en cuanto se aleja de la formalidad de la mayoría de las representa- 
ciones en la categoría convivencia, tal como se ve en la figura 6. Una de las desviaciones es la locación fuera de las instalaciones de la compañía. Una segunda la constituye el guiño a la tradición china y su historia, ya que se encuentran en un ícono nacional: la Gran Muralla.

\section{Figura 6. Caso desviado: informalidad en la convivencia}

\section{NOTICIAS Y EVENTOS}

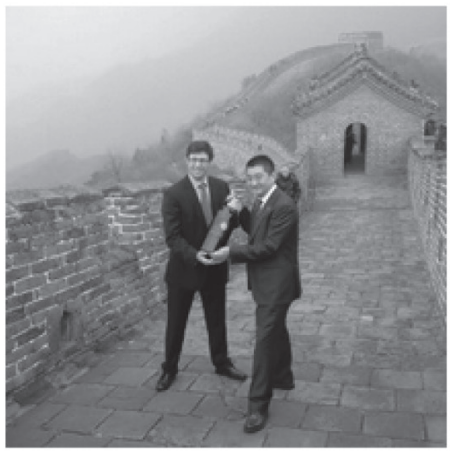

\section{GRAN GIRA Y LANZAMIENTOS EN CHINA}

En octubre COFCO comenzó su gira de lanzamiento con Viña Maipo "Greatwall", presentando oficialmente la relación entre ambas empresas. EL principal evento se llevó a cabo junto a los altos ejecutivos en Beijing, con un deslumbrante nivel de producción y despliegue de branding. El embajador de Chile describió este evento como un matrimonio entre dos grandes empresas que contribuyen a las relaciones bilaterales entre Chile y China.

Además se realizaron exitosos eventos, donde se desarrollaron tastings, wine dinners, media interview, en las ciudades de Chongqing, Yangzhou, Shanghai, Wuhan y Kunming. La gira continuará por más ciudades, introduciendo a Viña Maipo en la principal red de clientes.

\section{Imagen del enunciatario: visión del mercado}

El mercado chino se relaciona principalmente con el crecimiento económico de la compañía. El aumento de las ventas del producto comercializado en China se muestra como una meta alcanzable, y está relacionado con la expansión no solo comercial, sino también productiva de la compañía. Se representa con banderas o mapas y asociados al mundo asiático.

Otra característica presente es la idea de nuevas oportunidades de negocios para las compañías chilenas, que figuran el mercado asiático en general y el chino en específico como una oportunidad de crecimiento corporativo en distintas áreas (ver, por ejemplo, cómo se destacan los premios Chios en http://www.deaguirre.cl/reconocimientos/) 


\section{Imagen del enunciatario: contacto}

En general, el modo de contacto que ofrecen las compañías chilenas en sus sitios web está dirigido a un mercado global general, sin especificidad en su destinatario (formulario típico). Está disponible en español e inglés, no en chino; a pesar de existir la opción de cambiar al idioma chino el sitio, la sección de contacto no cambia y se mantiene en inglés (salvo una de las seis empresas analizadas). De este modo, se aprecia una baja preocupación de las compañías chilenas para dirigirse a las compañías chinas, a pesar de percibírseles como un mercado creciente y fuente de diversas oportunidades comerciales para su propio crecimiento.

\section{Imagen del enunciatario: modo en que se presenta la página}

Respecto del modo en que se presenta el sitio web de las compañías analizadas en idioma chino, se observa la persistencia de secciones en inglés que no están traducidas. Asimismo, en varios sitios web el material audiovisual que allí se ofrece está en general en inglés sin traducción al chino. Los escasos ejemplos de material audiovisual en chino no contienen un relato en ese idioma sino texto de apoyo a las imágenes.

\section{Discusión}

El caso de estudio nos muestra algunos aspectos interesantes que permiten dilucidar cómo las organizaciones vitivinícolas chilenas se representan la manera de generar confianza en sus públicos de interés o stakeholders desde la perspectiva metodológica del análisis del discurso y los marcos de sentido.

\section{El enunciador (1): la organización}

Desde el enunciador, nos damos cuenta de que las viñas analizadas se representan principalmente como organizaciones donde prima el liderazgo individual (ya sea del enólogo jefe o desde el fundador familiar) y, en menor medida, el liderazgo colectivo de sus integrantes. Esta dualidad podría reflejar - al menos en los casos observados - el cambio desde una sociedad colectivista propia de las culturas latinoamericanas a una más individualista, relacionada con culturas donde predomina la idea de avanzar hacia el desarrollo económico (Hofstede, 2014). China, en cambio, es considera- 
da como una cultura colectivista, característica que afecta la estructura relacional de sus organizaciones (Özer, Zheng y Ren, 2014).

Tomando en cuenta la importancia que la cultura nacional tiene en el desarrollo de la confianza (Doney, Cannon y Mullen, 1998), podemos inferir que en aquellas organizaciones donde predomina la imagen de un liderazgo de tipo individual — como algunas de las vitivinícolas chilenas aquí analizadas - puede considerarse un factor que afecta la construcción de identidad común con los stakeholders chinos. Por el contrario, aquellas organizaciones que proyectan en su imagen corporativa la valoración de una cultura colectivista, puede considerarse un factor que aporta a la identificación cultural con su contraparte china y, por ende, facilitar la confianza.

En el caso estudiado, el liderazgo se representa desde dos valores fundamentales que sostendrían la construcción de confianza. Una, la constituye la habilidad o competencia (Dietz y Gillespie, 2011) que aparece constantemente en los sitios web de las viñas chilenas analizadas a través del uso de determinado lenguaje de connotación positiva (en este caso "experiencia", "alto nivel"). Esto puede verse en la preponderancia que otorgan a las cualificaciones de las personas a cargo de hacer funcionar la viña en sus diversos estamentos, desde el trabajador hasta los miembros del directorio. El otro factor es la preponderancia que proyectan en sus sitios web a la imagen de familia y tradición, ambos elementos propios del confucianismo, que aún son factores importantes de las organizaciones chinas (Labarca, 2015).

Respecto de las representaciones en los sitios web de viñas chilenas sobre su infraestructura y procesos, aparecen factores relacionados con el concepto de confianza como resultado de procesos informativos y cognitivos (confianza estratégica) cuando se muestra - tanto visualmente como en el texto - como valor directivo la modernidad y la tecnología. Sin embargo, no menos importante y constitutivo de la confianza es el discurso identitario del enunciador en cuanto organización. En las organizaciones chilenas analizadas, esto aparece bajo las nociones de tradición y calidad humana, que, como se mencionó, son un elemento central en el contexto de la cultura nacional del destinatario. 
Las representaciones sobre las cuales las organizaciones proyectan su confiabilidad desde sus sitios web se basan tanto en procesos informativos y cognitivos como identitarios. Por un lado, se provee de gran cantidad de información técnica sobre sus productos y reconocimientos formales enológicos de la organización (triunfos, características, valor propio); por otro, se representa la organización sosteniendo valores y estándares de comportamiento moralmente aceptados asociados a la producción sustentable, cuidadosa con su entorno natural y social.

Por último, destacamos la imagen que proyectan las viñas acerca sus valores culturales locales y tradicionalistas. Para ello, muchas veces se desarrolla material corporativo específicamente destinado al mercado chino en cuanto utiliza su idioma.

Podemos concluir, entonces, que los enunciadores aquí estudiados - las organizaciones vitivinícolas chilenas - utilizan estrategias comunicacionales orientadas a la construcción de confianza mediante la proyección de una identidad común como mediante el uso de datos verificables que fomentan la confianza con sus destinatarios chinos.

\section{El enunciador (2): el producto}

Tal como en el enunciatario-organización, en este caso también los sitios web aportan abundante y detallada información del producto, desde información totalmente técnica hasta información de usabilidad (usos anexos al producto) para abarcar un amplio abanico de públicos. La información sobre el producto es validada mediante su relacionamiento con procesos de producción de alta calidad y bien evaluados en concursos internacionales de enología. Allí el valor del producto radica en la especificidad de su cosecha, almacenaje, vinificación, etc. Respecto de la puesta en valor, se basa en dos atributos principales: calidad y exclusividad, que, como ha sido demostrado por trabajos previos, son dos atributos relevantes para el consumidor chino que puede acceder al consumo de vinos (Hiu et al., 2005; Wang et al., 2009).

\section{El enunciatario: la contraparte china}

Finalmente, se analiza desde la información provista por el enunciador, la percepción y el tipo de vínculo que proyecta con el enunciatario, en este 
caso, los stakeholders chinos. Es necesario primero explicar que la representación de los stakeholders chinos, tal como hemos explicitado en trabajos anteriores (Labarca y Rojas, 2015), se delimita a la idea de contraparte en los negocios (dada la estructura del comercio chino chileno en el que la interacción se da mayoritariamente con la empresa importadora o el trader) y por tanto al comercio B2B. Así, los stakeholders chinos a quienes orientan sus estrategias comunicacionales las organizaciones chilenas aquí analizadas corresponden a su interacción con distribuidores o potenciales socios comerciales. Esta interacción, como vimos, se muestra principalmente asociada a instancias formales de encuentro entre los representantes de las organizaciones chilenas y chinas. De este modo, los encuentros informales quedan al margen de las estrategias comunicacionales implementadas en los sitios web de las organizaciones analizadas, lo cual se contrapone a la abundante literatura existente respecto de la importancia de la informalidad en los negocios chinos y las redes de negocios (Fang, 1999; Graham y Lam, 2003; Labarca y Rojas, 2015). Asimismo, destaca la representación mayoritaria de los empresarios chinos en su vestimenta y actitudes como correspondiendo a modos culturales de Occidente. De este modo, se identifican culturalmente los ejecutivos de las organizaciones chinas con los de las organizaciones chilenas, que proyectan una imagen de comunidad basada en la idea común de empresarios que interactúan en un mundo global con cánones y códigos similares.

En el mercado, China se enmarca en un contexto asiático de oportunidades, donde se la asocia al crecimiento y a alternativas comerciales, pero sin tener una preponderancia en forma individual. Así, advertimos que la imagen del mercado chino está ausente de las estrategias comunicacionales de las organizaciones chilenas.

La interacción que se muestra en los sitios web de las organizaciones chilenas con sus stakeholders chinos es bastante escasa, así como es escaso el uso del lenguaje chino. De hecho, aunque exista una versión china en los sitios web, parte importante de ella sigue el patrón del contenido presentado en inglés (incluso una traducción exacta). Esto indica la proyección de una imagen corporativa occidentalizada y donde domina el inglés. La imagen 
del mercado chino y la limitada versión en su idioma pueden ser interpretadas como una falta de adaptación de la comunicación de la organización a la cultura china dentro de la estrategia comunicacional de las organizaciones chilenas analizadas.

De lo anterior se desprende que la comunicación corporativa, en el caso examinado, contiene elementos relacionados con información que apuntan a la confianza cognitiva y también a elementos de identificación común que buscan generar una suerte de comunidad, una confianza moral más allá de lo racional e instrumental. Sin embargo, los elementos vitales como la adaptación del mensaje a los códigos culturales chinos parecen ausentes.

Las comunicaciones realzan aspectos de la dimensión estratégica de la construcción de confianza, como la abundante y detallada información tanto sobre los aspectos técnicos del proceso productivo de la organización como sobre sus productos. Es muy importante considerar esto, puesto que el crecimiento del comercio bilateral es relativamente reciente y exige datos verificables sobre las organizaciones con las que se comercia para el aseguramiento de buenos resultados del intercambio.

En segundo lugar, tanto la importancia dada a temáticas de responsabilidad social corporativa, la calidad de los productos elaborados y su interacción sustentable con el entorno, así como la representación de la contraparte china como un igual en cuanto ejecutivos y hombres de negocios, denotan también un intento de crear una identidad común basada en valores morales compartidos.

\section{Conclusiones y contribuciones}

Como explica Sollow (2000), los temas blandos como la confianza son aún debatidos por la literatura, porque se subestiman (Nooteboom, 2002) debido a la dificultad que presenta medir y operacionalizar el concepto de confianza. De hecho, la mayoría de las investigaciones de confianza (de tipo cuantitativo, por ejemplo) se centran en comprender la confianza como una actitud acotada a ciertos parámetros culturales occidentales, lo cual entrega escasa información desde el punto de vista de la gestión de la 
comunicación corporativa multicultural, aparte de una percepción global y agregada sobre una organización. Desde lo cualitativo, y considerándolo aun una metodología que debe perfeccionarse, este trabajo puede ser un aporte metodológico al estudio de los factores que contribuyen a la construcción de confianza en un contexto de relaciones internacionales de intercambio económico. Este permite analizar en forma sistemática algunos elementos que forman parte del producto comunicacional de organizaciones insertas en dicho contexto. En este caso, las matrices de análisis se han aplicado a las páginas web corporativas de casos representativos de la industria vitivinícola, debido a que los sitios web se consideran una de las herramientas más poderosas de comunicación en el mundo global. Resta por analizar cómo puede perfeccionarse para ser aplicada en otras industrias y en otros productos comunicacionales.

Desde el punto de vista teórico —y entendiendo que cada vez más las organizaciones necesitan una vinculación estratégica con sus públicos y generar confianza con ellos a través de la comunicación-, se propone la necesidad de entender la confianza como una variable multidimensional que reconoce aspectos informativos (cognitivos, racionales), pero también desde una perspectiva menos racional, donde los valores comunes generan una identidad que, si bien podría argumentarse, tiene fines estratégicos, facilita la interacción y el comportamiento no oportunista entre las partes. Así, la discusión sobre el concepto de confianza moralista (asociado este a la idea de confianza generalizada), en contraposición al concepto de confianza racional (asociada a una confianza de índole privada) propuesta por Uslaner (2002), pierde relevancia en el contexto de las comunicaciones corporativas de organizaciones chilenas del rubro vitivinícola. La confianza entre las organizaciones se sostiene también sobre un discurso de tipo moral e identitario y, por tanto, deja de ser un elemento constitutivo solo de la llamada confianza generalizada. A esto se suma que en el caso aquí analizado vemos que, si bien existen algunos elementos que tienden desde el enunciador a reforzar vínculos identitarios de confianza a través de la comunicación, existe escasa representación del destinatario, y se le reduce a instancias formales o a la conceptualización de China como mercado, lo cual debilita la construcción de confianza entre ambas partes. 
Más aún, la misma discusión de la creación de confianza en un contexto de relacionamiento corporativo internacional pone de manifiesto, como dijeran Valentini y Kruckeberg (2011), que la construcción de confianza moral es un aspecto clave de la sociedad posmoderna y globalizada.

De esta forma, las organizaciones chilenas debieran profundizar - sobre todo en el ámbito de la industria vitivinícola, clave en la formación de la imagen país - en elementos comunicacionales que contribuyan a generar lazos de confianza en los dos puntos anteriores: por un lado, relevando la existencia del enunciatario como parte importante de los objetivos comunicacionales de la organización y, por otro, entregando mayores elementos que permitan construir una confianza de tipo moral, en la que exista comunión entre los valores del enunciador y aquellos estimados por el destinatario.

Finalmente, y para tratar el tema que preocupa a la industria enunciado al inicio de este artículo, el análisis lleva a deducir que la preocupación por posicionar la industria chilena vitivinícola como premium puede entenderse también desde ambos conceptos (identitarios y cognitivos). El relevo del cuidado del medio ambiente y la sustentabilidad puede asociarse a generar confianza y lazos que aporten a esta percepción desde la propia identidad, ya que muestra una industria que se preocupa más allá de la generación del producto. Asimismo, el énfasis puesto en los premios y la calidad (a través de información relevante y clara) apunta a mejorar la confianza por medio de elementos cognitivos. Resta, sin embargo, profundizar en este análisis a más empresas y realizar un seguimiento en el tiempo para ver resultados más concretos.

\section{Referencias}

Abril, G. (1994). Análisis semiótico del discurso. En J. M. Gutiérrez y J. Delgado, Métodos y técnicas cualitativas de investigación en ciencias sociales (pp. 427-464). Madrid: Síntesis.

Axelrod, R. (1984). The evolution of cooperation. Nueva York: Basic Book Publishers. 
Bachmann, R. (2006). Trust and/or power: Towards a sociological theory of organizational relationships. En R. Bachmann y A. Zaheer (eds.), Handbook of trust research (pp.393-408). Cheltenham: Edward Elgar.

Benveniste, E. (1977). Problemas de lingüística general (vol. 1). México: Siglo XXI.

Capriotti, P. (2009). Branding corporativo: fundamentos para la gestión estratégica de la identidad corporativa. Santiago de Chile: Business School Universidad Mayor.

Capriotti, P. y Moreno, A. (2007). Corporate citizenship and public relations: The importance and interactivity of social responsibility issues on corporate websites. Public Relations Review, 33(1), 84-91.

Carreras, E., Alloza, Á. y Carreras, A. (2013). Reputación corporativa. Madrid: LID.

Cersosimo, D. y Nistico, R. (2008). Social capital in economics. En D. Castiglione, J. van Deth y G. Wolleb (eds.), The handbook of social capital (pp. 386-410). Nueva York: Oxford University Press.

Child, J. (2001). Trust - the fundamental bond in global collaboration. Organizational Dynamics 29(4), 274-288

Coleman, J. (1988). Social capital in the creation of human capital. American Journal of Sociology, 94, S95-S120.

Coleman, J. (1990). Foundations of social theory. Cambridge, Mass., Londres: Belknap Press of Harvard University Press.

Cornelissen, J. (2011). Corporate communication: A guide to theory and practice. Londres: Sage.

Denzin, N. y Lincoln, Y. (eds.) (2000). Handbook of qualitative research (3. ${ }^{\text {a }}$ ed.). Thousand Oaks, CA: Sage. 
Dietz, G. y Gillespie, N. (2011). The Recovery of Trust: Case studies of organisational failures and trust repair. Ocassional Paper, 5. Institute of Business Ethics. Recuperado de http://www.ibe.org.uk/userfiles/op_trustcasestudies.pdf

Ding, Z., Au, K. y Chiang, F. (2015). Social trust and angel investors' decisions: A multilevel analysis across nations. Journal of Business Venturing, 30(2), 307-321.

Doney, P. M., Cannon, J. P. y Mullen, M. R. (1998). Understanding the influence of national culture on the development of trust. Academy of Management Review, 23(3), 601-620.

Dowling, J. (2012). La industria vitivinícola de Chile: calidad premium. Revista Business Chile. Recuperado de http://www.amchamchile. cl/2012/08/la-industria-vitivinicola-de-chile-calidad-premium/

Economía y Negocios (2015). Exportaciones de vino chileno a China subieron $122 \%$ en julio. Recuperado de http:/ / www.economiaynegocios.cl/noticias/noticias.asp?id=179744

Fang, T. (1999). Chinese business negotiating style. Thousand Oaks, California, Londres: Sage.

Felzenstein, C. (2008). All ways surprising. En K. Dinnie (ed.), Nation branding: Concepts, issues, practice (pp. 59-61). Nueva York: Routledge.

Freeman, R. (1984). Strategic management: A stakeholder approach. Boston: Pitman.

Freeman, R. (2010). Stakeholder theory: The state of the art. Cambridge: Cambridge University Press.

Fukuyama, F. (1995). Trust: The social virtues and the creation of prosperity. Londres: Hamish Hamilton. 
Gambetta, D. (1988). Can we trust trust? En D. Gambetta (ed.), Trust: Making and breaking cooperative relations (pp. 213-237). Oxford: Basil Blackwell.

Gobierno de Chile, Dirección General de Relaciones Económicas Internacionales (2015). Análisis de las relaciones comerciales entre Chile y China en el marco del Tratado de Libre Comercio. Recuperado de https://www.direcon.gob.cl/wp-content/uploads/2015/08/AN-LISIS-RELACIONES-COMERCIALES-CHILE-CHINA.pdf

Gómez Lorenzini, P. (2009). Chile 2000-2006: la propuesta política del presidente Ricardo Lagos. Análisis semiótico de los mensajes a la nación (Tesis de doctorado, Universidad Complutense de Madrid, Madrid, España).

Granovetter, M. (1985). Economic action and social structure: The problem of embeddedness. The American Journal of Sociology, 91(3), 481-510.

Gutiérrez-García, E. (2010). Gobierno corporativo y comunicación empresarial: ¿qué papel cumplen los directores de comunicación en España? Palabra Clave, 13(1), 147-160.

Hardin, R. (2002). Trust and trustworthiness. Nueva York: Russell Sage Foundation.

Hardy, C., Phillips, N. y Lawrence, T. (1998). Distinguishing Trust and power in interorganizational relations: Forms and facades of trust. En C. Lane (ed.), Trust within and between organizations (pp. 6487). Oxford: Oxford University Press.

Hiu, A. S., Siu, N. Y., Wang, C. C. y Chang, L. M. (2001). An investigation of decision-making styles of consumers in China. Journal of Consumer Affairs, 35(2), 326-345.

Hofstede, G. (s. f.). What about Chile? Recuperado de http://geert-hofstede.com/chile.html 
Hong, S. Y. y Rim, H. (2010). The influence of customer use of corporate websites: Corporate social responsibility, trust, and word-ofmouth communication. Public Relations Review, 36(4), 389-391.

Inglehart, R., Basáñez, M., Díez-Medrano, J., Halman, L. y Luijkx, R. (2004). Human beliefs and Values: A cross-cultural sourcebook based on the 1999-2002 values surveys. México: Siglo XXI.

Isham, J., Kelly, T. y Ramaswamy, S. (eds.) (2002). Social capital and economic development: Well-being in developing countries. Cheltenham: Edward Elgar Publishing.

Kim, S. E. (2005). The role of trust in the modern administrative state an integrative model. Administration \& Society, 37(5), 611-635.

Kramer, R. M., Brewer, M. B. y Hanna, B. A. (1996). Collective trust and collective action: The decision to trust as a social decision. En R. Kramer y T. Tyler (eds.), Trust in organizations: Frontiers of theory and research (pp. 357-389). Thousand Oaks, Londres: Sage.

Kramer, R. M. y Cook, K. S. (eds.) (2004). Trust and distrust in organizations: Dilemmas and approaches. Nueva Yok: Russell Sage Foundation.

Labarca, C. (2008). La confianza y la reputación como variables de Imagen País. Cuadernos de Información 23, 72-81.

Labarca, C. (2012). A model for trust building: The state, market and cultural norms in Sino-Chilean economic exchange (PhD), School of Government and International Affairs, Durham University.

Labarca, C. (2015). Ni Hao Mr. Pérez, Buenos días Mr. Li. Santiago: Ediciones UC.

Labarca, C. y Rojas, R. (2015) Cultural and global perspectives to stakeholder management in International Public Relations: The Sino 
Chilean case study. En Communication Across the Life Span. Ponencia presentada en la International Commuication Association, San Juan, Puerto Rico.

Lakoff, G. (2004). Don't think of an elephant: Know your values and frame the debate. White River Junction: Chelsea Green Pub. Co.

Lam, M. N. y Graham, J. L. (2003). Negociación a la manera china. Harvard Business Review, 81(10), 68-79.

Luhmann, N. (1979). Trust and power: Two works. Chichester: Wiley.

Maingueneau, D. (1980). Introducción a los métodos de análisis del discurso: problemas y perspectivas. París: Hachette.

Maynard, M. y Tian, Y. (2004). Between global and glocal: Content analysis of the Chinese web sites of the 100 top global brands. Public Relations Review, 30(3), 285-291.

Nooteboom, B. (2002). Trust: Forms, foundations, functions, failures and figures. Cheltenham, Edward Elgar.

Ochieng, E. G. y Price, A. D. F. (2010). Managing cross-cultural communication in multicultural construction project teams: The case of Kenya and UK. International Journal of Project Management, 28(5), 449-460.

Özer, Ö., Zheng, Y. y Ren, Y. (2014). Trust, trustworthiness, and information sharing in supply chains bridging China and the United States. Management Science, 60(10), 2435-2460.

Patton, M. (1990). Qualitative evaluation and research methods. Beverly Hills: Sage.

Peñamarín, C. (1997). El análisis de textos en una nueva clave: discursos e imágenes sobre la inmigración en EL PAÍS. CIC Cuadernos de Información y Comunicación, 3, 145-166. 
Putnam, R. (2000). Bowling alone: The Collapse and revival of American community. Nueva York: Simon y Schuster.

Putnam, R. (2002). Democracies in flux: The evolution of social capital in contemporary society. Oxford: Oxford University Press.

Putnam, R. (2007). E pluribus unum: Diversity and community in the twenty-first century the 2006 Johan Skytte Prize Lecture. Scandinavian Political Studies, 30(2), 137-174.

Rodrigo, M. (1999). La comunicación intercultural. Barcelona: Anthropos.

Schwandt, T. (2000). Three epistemological stances for qualitative inquiry: Interpretivism, hermeneutics, and social constructionism. En N. Denzin y I. Lincoln (eds.), Handbook of qualitative research (pp. 189213). Thousand Oaks, Londres, Nueva Delhi: Sage Publications.

Sollow, R. (2000). Notes on social capital and economic performance. En P. Dasgupta y I. Serageldin (eds.), Social capital: A multifaceted perspective (pp. 6-10). Washington DC: World Bank.

Somma, N., Labarca, C., Gálvez, M. y Godoy, S. (2016). ¿Qué ocurre con la confianza cuando los gobiernos locales se vuelven virtuales? Explorando los determinantes de la confianza en sitios web municipales en Chile. Comunicación y Sociedad, 25, 157-182.

Swift, T. (2001). Trust, reputation and corporate accountability to stakeholders. Business Ethics: A European Review, 10(1), 16-26.

Tironi, E. y Cavallo, A. (2007). Comunicación estratégica: vivir en un mundo de señales. Madrid: Taurus.

Top, M., Akdere, M. y Tarcan, M. (2015). Examining transformational leadership, job satisfaction, organizational commitment and organi- 
zational trust in Turkish hospitals: Public servants versus private sector employees. The International Journal of Human Resource Management, 26(9), 1259-1282.

Uslaner, E. (2002). The moral foundations of trust. Cambridge: Cambridge University Press.

Valentini, C. y Kruckeberg, D. (2011). Public relations and trust in contemporary global society: A Luhmannian perspective of the role of public relations. Central European Journal of Communication, 4(6), 91-107.

Van de Ven, A. y Smith, P. (2006). Relying on trust in cooperative inter-organizational relationships. En R. Bachmann y A. Zaheer (eds.), Handbook of trust research (pp. 144-164). Cheltenham: Edward Elgar.

Van Riel, C. y Fombrun, C. (2007). Essentials of corporate communication: Implementing practices for effective reputation management. Londres: Routledge.

Verón, E. (1984). Cuando leer es hacer: la enunciación en el discurso de la prensa gráfica. En E. Verón, Fragmentos de un discurso. Barcelona: Gedisa.

Viñarás Abad, M. (2013). Estrategias de comunicación para generar confianza. Comunicación y Hombre: Revista Interdisciplinar de Ciencias de la Comunicación y Humanidades, 9, 59-73.

Wang, F., Zhang, J., Mu, W., Fu, Z. y Zhang, X. (2009). Consumers' perception toward quality and safety of fishery products, Beijing, China. Food Control, 20(10), 918-922.

Yamagishi, T. y Yamagishi, M. (1994). Trust and commitment in the United States and Japan. Motivation and Emotion, 18(2), 129-166. 
Yamagishi, T. (2001). Trust as a form of social intelligence. En K. Cook (ed.), Trust in society (pp. 121-147). Nueva York, Russell Sage Foundation.

Yamagishi, T. (2011). Trust: The evolutionary game of mind and society. Tokio: Springer.

Zak, P. J. y Knack, S. (2001). Trust and growth. The Economic Journal, 111(470), 295-321. 